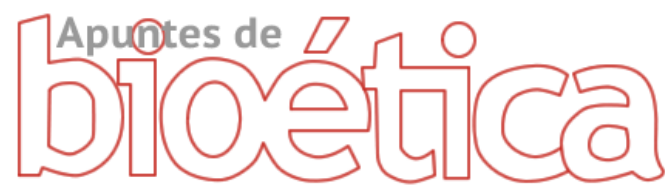

https://doi.org/10.35383/apuntes.v2i2.281

\title{
El fútbol de los que sobran: apuntes sobre la necesidad de nuevas concepciones éticas en relación al desarrollo humano de los deportistas de élite
}

\author{
Aldo Alesandro Santome Sánchez ${ }^{1}$
}

\section{INFORMACIÓN DEL ARTÍCULO RESUMEN}

\section{Historia del artículo:}

Recibido el 11 de setiembre de 2019

Aceptado el 02 de diciembre de 2019

\section{Palabras claves:}

Desarrollo Humano

Deporte

Fútbol

Utilitarismo

Personalismo
En el presente artículo se busca reflexionar sobre el fenómeno del fútbol en la actualidad, analizándolo no solo como una actividad deportiva, sino como un espectáculo global y como una de las industrias que más dinero circula. En medio de ese contexto, hacemos hincapié en la situación de los futbolistas de élite, quienes, debido a la visión mercantilista que proponen varias instituciones deportivas, son vistos como las principales herramientas de obtención de riqueza, obviando su desarrollo personal.

The football of the outsiders: Notes about the new ethical conceptions related to the human development of elite athletes

ABSTRACT

\section{Keywords:}

Human Development

Sport

Football

Utilitarism

Personalism
This article has carried out a reflection about the phenomenon of football today, analyzing no just like a sport activity, but as a global show and as one of the industries that circulates the most money. In the middle of that context, we did emphasis on the situation of the elite footballers, who, due to the mercantilist vision proposed by several sports institutions, are seen as the main tools to obtain wealth, forgetting your personal development.

\footnotetext{
1 Abogado por la Pontificia Universidad Católica del Perú. Actual alumno de la Maestría de "Persona, Matrimonio y Familia" de la Universidad Católica Santo Toribio de Mogrovejo (USAT). Email: asantome@pucp.pe. ORCID: https://orcid.org/0000-0002-5208-6489
} 


\section{Introducción}

Desde hace varias décadas el deporte ha cambiado de manera considerable. Así, hemos sido testigos de cómo, de manera intempestiva, una nueva manera de concebir, tanto a la competencia como a los deportistas, ha terminado por consolidarse dentro de la sociedad actual.

Si se va al origen de las primeras competencias deportivas, se podrá notar la alta relevancia que las primeras sociedades daban a la exaltación de las virtudes humanas. Al respecto, como indica García Romero, el deporte en la antigua Grecia se caracterizaba por un claro sesgo humanista, haciendo del deporte una cuestión de culto (2009, p.11). De esta forma, el deporte no solo era visto como un espectáculo de masas, sino que tenía un significado más profundo y que demandaba en los atletas una preparación más allá de la física.

Al respecto, García Romero utiliza los escritos del pensador Píndaro de Tebas para poder describir al atleta griego:

Para Píndaro el atleta es el hombre ideal, la más perfecta plasmación del aristócrata, tal como lo concibe el poeta, a saber, el hombre que destaca tanto por sus cualidades físicas como por sus cualidades intelectuales $y$ morales, puestas siempre al servicio de la comunidad, en beneficio de la buena marcha de los asuntos de su ciudad. El hecho de que Píndaro nos presente a los vencedores en los juegos deportivos como modelos de conducta (e, insisto, no sólo en lo físico, sino sobre todo en el terreno moral) tiene su fundamento en la convicción de que la competición atlética es un test muy fiable para evaluar la valía de un hombre, pues en ella el ser humano saca a relucir lo mejor de sí mismo (2009, p.13).

A partir de lo anterior, podríamos decir que el deporte en la antigüedad era una actividad de conexión con las mayores virtudes morales del atleta, cultivando no solo el esfuerzo físico, sino también un equilibrio integral (de allí viene la célebre frase "Mens sana in corporte sano", que proponía la salud integral de mente, cuerpo y alma).

Sin embargo, ya con el pasar de los años, el deporte fue cambiando dentro del mundo antiguo. Así, en el siglo V a.C, surgieron una serie de variantes en la percepción del deporte y el rol de los atletas. Al respecto, García Romero menciona que surgieron dos principales problemas:

En primer lugar, la exagerada valoración social de las cualidades físicas por encima de las intelectuales, que se traducía, como ahora, en las desmesuradas recompensas económicas que recibían los atletas y en la devoción popular de que eran objeto, sobre todo en comparación con las menores satisfacciones que aguardaban a quienes cultivaban el espíritu más que el cuerpo; en segundo lugar, el régimen de vida que los deportistas se veían obligados a seguir, cuyos excesos en la alimentación y en los esfuerzos físicos resultaban ser, en última instancia, sumamente perjudiciales para la salud y en modo alguno contribuían (sino todo lo contrario) a la formación de un cuerpo bello y armonioso (2009, pp.14-15).

De ese modo, fue en esa época donde comenzaron a surgir las primeras competencias que, en lugar de ser motivadas por el espíritu religioso o virtuoso de los deportistas, eran organizadas como un mero espectáculo que, en muchos casos, exponía a los atletas a competencias infrahumanas.

En consecuencia, se comenzó a prestar más atención al deporte como espectáculo que al deporte como espacio de cultivo de las virtudes. Es decir, el deportista, en tanto 
persona, comenzó a estar en un segundo plano y comenzó a elevarse su figura como la de un "héroe", el cual, si bien era admirado y aclamado por multitudes, era expuesto a situaciones que comenzaron a ponerse en práctica como la de los gladiadores, donde, literalmente, los deportistas eran exigidos hasta la muerte.

Hoy, si bien ya no vemos gladiadores ni peleas hasta la muerte -debido a la concientización sobre los derechos humanos-, esto no obsta para que sigamos viendo, pero de otra forma, cómo los deportistas siguen sufriendo una serie de tratos arbitrarios por favorecer otro tipo de intereses ajenos al deporte.

\section{Metodología}

\section{Paradigma, método y diseño de investigación}

La presente investigación contendrá un paradigma crítico frente a la situación problemática planteada. Del mismo modo, se llevará a cabo un método etnográfico, puesto que haremos un análisis de una situación en referencia a un colectivo en concreto, en este caso los futbolistas. Por último, respecto al diseño de la investigación, está se determinará a partir de la explicación de la toma de bibliografía y la reflexión derivada de esta.

\section{Sujetos u objetos de la investigación}

Los sujetos sobre los que se investigarán son los futbolistas de élite, los cuales, como plantearemos, pasan por un proceso de deshumanización en relación al ejercicio de sus libertades individuales.

\section{Procedimiento de recolección de datos cualitativos}

\section{- Técnica de recolección de datos}

Se usará bibliografía especializada en la materia, la cual podría aportar interesantes puntos de vista al análisis de la situación problemática planteada.

\section{- Procesamiento de datos}

Se hará un análisis de la realidad descrita en la situación problemática en contraste con los datos obtenidos de la bibliografía propuesta y de las reflexiones derivadas de esta.

\section{Resultados, análisis y discusión}

1. Las concepciones utilitaristas actuales y la "cultura del descarte"

Como es de conocimiento público, vivimos en una época donde la gran mayoría de fenómenos sociales se mueven alrededor del factor económico. Sobre esto, el Papa Francisco ha venido denunciando, como consecuencia de este pensamiento, la creación de una "cultura del descarte". Al respecto:

Una de las causas de esta situación se encuentra en la relación que hemos establecido con el dinero, ya que aceptamos pacíficamente su predominio sobre nosotros y nuestras sociedades. La crisis financiera que atravesamos nos hace olvidar que en su origen hay una profunda crisis antropológica: ila negación de la primacía del ser humano! Hemos creado nuevos ídolos. La adoración del antiguo becerro de oro (cf. Ex 32,1-35) ha encontrado una versión nueva y despiadada en el fetichismo del dinero y en la dictadura de la 
economía sin un rostro y $\sin$ un objetivo verdaderamente humano. La crisis mundial, que afecta a las finanzas y a la economía, pone de manifiesto sus desequilibrios $y$, sobre todo, la grave carencia de su orientación antropológica que reduce al ser humano a una sola de sus necesidades: el consumo (Evangelii gaudium, 55).

Sobre el particular, podríamos mencionar que las reflexiones que hace el Papa sobre esta "sociedad del descarte" y cómo se ha venido generando una crisis humanitaria, nos rememoran también a las reflexiones que hace Zygmunt Bauman en relación a lo que él denomina una "sociedad líquida". Al respecto, dicho autor afirma lo siguiente:

La nuestra es una sociedad de consumo: en ella la cultura al igual que el resto del mundo experimentado por los consumidores, se manifiesta como un depósito de bienes concebidos para el consumo, todos ellos en competencia por la atención insoportablemente fugaz y distraída de los potenciales clientes, empeñados en captar esa atención más allá del pestañeo $(2013$, p.19).

Al respecto de ambas reflexiones podríamos colegir muchas cuestiones. Sobre el particular, consideramos que ambos pensadores buscan denunciar y concientizar a la población sobre los riesgos de esta tendencia actual de priorizar el consumo de ciertos bienes, lo cual, podría conllevar, entre otras cosas, al aprovechamiento de ciertas personas.

A propósito de ello, la tendencia mencionada la podemos ver reflejada en los actuales índices de desarrollo humano, donde, pareciera que el principal factor a tomar en cuenta para determinar la calidad de vida de las personas es el consumo y posesión de determinados bienes.

Así, aquellas personas que superen cierta tope de ingresos o que tengan determinada capacidad adquisitiva serán consideradas más plenas que otras que nos los tengan, independientemente de otras cuestiones ${ }^{2}$.

Entonces, podemos ver que este modelo de consumo, el cual trae consigo una deshumanización de la persona -quien pasa a ser también un objeto del mismo y que podría comercializar no solo su esfuerzo físico, sino cuestiones como su intimidad, su capacidad de tomar decisiones, su imagen, etc.

Ahora, todo esto resulta más preocupante cuando esta "cultura del descarte" es asimilada y arraigada en la percepción que cada persona hace de la realidad. Al respecto, Augusto Ponzio hace, a partir de la influencia de Noam Chomsky, una reflexión sobre cómo el escenario influye activamente en la percepción del individuo.

Sobre ello, el autor afirma que el individuo es un agente que adapta pasivamente los códigos vigentes en su escenario, por lo que sería un simple usuario de una estructura ya constituida de ideas que no comprende y de la que no es autor, sino que se erige a partir de ideologías o ideas que no le son propias y a cuyo

\footnotetext{
Al respecto de lo anterior, Martha Nussbaum ya venía denunciando lo mencionado:

Ese modelo aún sigue vigente. Aunque donde más arraigados se encuentra es en los análisis convencionales del rendimiento de los países en vías de desarrollo (es decir, en la vertiente práctica de la economía de desarrollo y en los organismos relacionados con esta, como el Fondo Monetario Internacional (FMI) y el Banco Mundial), también se recurre a él en abundancia para reflexionar sobre la situación de las naciones ricas y sobre lo que significa para estas "desarrollarse" o mejorar su calidad de vida" $(2012,13)$.
} 
mantenimiento contribuye indirectamente (Ponzio, 1974, 28).

De ese modo, esta cultura del consumo que adquiere vigencia dentro de la percepción de las personas en la actualidad, ha provocado que muchas veces sin tener una intención directa, las personas nos hagamos partícipes de esta, adaptando los preceptos de este sistema que ya está consolidado y que se asume como único e incuestionable.

\section{La actualidad en el mundo deportivo}

Al respecto, podemos apreciar cada vez con más intensidad, que muchos atletas buscan introducirse en el mundo deportivo buscando aspirar al tan ansiado desarrollo económico que esta sociedad de consumo les ofrece. $Y$ es que, en los últimos años, hemos podido ver cómo el marketing y la economía han terminado por convertir a estrellas futbolísticas en meras marcas deportivas que pueden valer hasta 100 o 200 millones de dólares ${ }^{3}$.

No obstante, parafraseando una vieja frase de Oscar Wilde, pareciera que todos los futbolistas de hoy en día, si bien tienen un precio, parece que ninguno tiene un valor. Son percibidos como máquinas a las que no se les permite fallar, debiendo obtener resultados desde el primer instante de competencia, y, de no obtenerlo, dejan de ser útiles para su equipo, por lo que se les podría, rememorando las palabras del Papa, "descartar".

Al respecto, Ángel Cappa, conocido entrenador deportivo, afirma, citando a

\footnotetext{
3 Es más, al tiempo de esta redacción, según la prestigiosa web Transfermarkt, el francés Kylian Mbappé es el actual jugador más caro del mundo con un valor de 200 millones de euros. Cabe indicar, que el futbolista francés actualmente tiene solo 20 años y viene de ser uno de los mejores jugadores del último mundial de fútbol, donde su selección se consagraría como campeona del mundo (Transfermarkt, 2019).
}

Edward Luttwark, lo siguiente respecto a este nuevo rol que se le da al factor económico:

No solo conquista mercados y relaciones económicas, sino que también extiende el radio de acción del mercado introduciéndolo en toda la esfera de la actividad humana. Con ello, los contenidos de la medicina, el arte, la literatura, y el deporte -por poner algunos ejemplos- se deforman por completo: se eliminan sus satisfacciones personales originales, todas las motivaciones desinteresadas y las fronteras éticas, y se sustituyen por dinero, a menudo montañas de él, aunque no está necesariamente destinado a los protagonistas (2004, pág. 29).

Como bien menciona Cappa, hemos pasado a una época donde la vida de los deportistas depende de algunos empresarios, quienes serán los principales encargados de tomar decisiones sobre la vida de aquellos, basándose, en la mayoría de los casos, en la cantidad de capital que podrían percibir a costa de la imagen y el esfuerzo del atleta.

De ese modo, cuestiones como en qué equipo jugarán el siguiente año, qué tipo de automóvil usarán, que marca de ropa comprarán, dónde vivirán, las fotos que podrán subir a las redes sociales, entre otras, dependerán únicamente del criterio de unos cuantos hombres de negocio, mas no del individuo en cuestión, debiendo ceder su autonomía y capacidad de decisión a estos empresarios si es que quiere hacerse un nombre dentro del mundo deportivo.

Bajo lo anterior, que no sorprenda que la gran cantidad de decisiones que se toman dentro de un club deportivo se hagan, ya no 
bajo criterios deportivos, sino bajo criterios de marketing. De esta manera, se decidirá si cierto jugador debe jugar o no en el equipo basándose en qué tan conocido es para la gente compraría sus camisetas, a qué tan agraciado es, a cómo maneja sus redes sociales, etc.

Y posteriormente, si un determinado jugador llega a ser contratado por el mencionado equipo, debe conocer que su imagen ahora será manejada por todo un equipo de publicidad que tomará las decisiones por él, para no manchar su reputación ni la del equipo.

Al respecto, Jorge Valdano, ex entrenador y directivo del Real Madrid, ya venía advirtiendo de los posibles riesgos de esta manera de concebir el mundo deportivo hoy en día. Al respecto, él menciona lo siguiente:

La importancia del dinero en el fútbol profesional es indiscutible, pero no conviene convertir el juego en algo secundario. Sin embargo, cada día es más difícil que un club equilibre estas dos esferas de poder. O se impone el área deportiva, lo que pone en peligro la economía $y$, por tanto, la supervivencia de un club, o toma el mando la parte financiera, y los jugadores terminan siendo un instrumento de marketing antes que deportistas entregados a su equipo y a su tarea. Son estratégicos si venden camisetas y dejan de serlo cuando pasan de moda. Hasta que las dos miradas confluyan, será difícil salir de esa dinámica malsana (Valdano, 2016, pág. 156).

Como dijimos, el deporte ya no sigue el rumbo bajo el que fue creado - que se entendía estaba relacionado con las virtudes humanas - sino que ahora se guía bajo otros parámetros, creando nuevos personajes, como los empresarios o representantes, que pasarán a tener protagonismo sobre las decisiones que se tomen en el ámbito deportivo.

Incluso lo anterior podría llevar a que se tomen decisiones sobre la vida del futbolista que no necesariamente acarreen un beneficio deportivo para este, sino todo lo contrario. Al respecto, podría mencionar dos ejemplos, por un lado, están los deportistas que, debido al asesoramiento financiero que reciben $y$ las millonarias ofertas que aceptan sus representantes, son destinados a ligas de menor nivel (como la liga de China o la liga de Arabia), ignorando que su nivel deportivo puede que no mejore en dichos países y que, todo lo contrario, termine por estancarse ${ }^{4}$.

El otro ejemplo involucra a los aspirantes a futbolistas, adolescentes entre los 12 y 18 años que ya se preparan en instituciones deportivas, quienes en estos tiempos son sobreexpuestos dentro del mercado, buscando ser vendidos a corta edad a clubes del extranjero sin medir debidamente su preparación física ni psicológica, exponiéndolos a un escenario donde, si es que no obtienen resultados a corto plazo, terminen por regresar a sus países de origen bajo el rótulo de "fracaso".

\footnotetext{
${ }^{4}$ Sobre el particular, destacamos las declaraciones del ex futbolista costamarfileño Yaya Touré, quien, en una entrevista a un diario español dijo lo siguiente respecto de la decisión de muchos de sus compañeros de irse a jugar a estas ligas solo por el dinero:

"Siempre digo que si yo fuera a China, acabaría arrepintiéndome. ¿Juegas al fútbol porque amas el deporte o porque lo que quieres es ganar dinero? Juego al fútbol para disfrutar de este entorno. Me encanta jugar. Me encanta ayudar a mis compañeros de equipo, me encanta jugar contra los mejores jugadores y equipos. Algunas personas se van allí para probar algo diferente" (Touré, 2017).
} 


\section{La "puerta giratoria"}

Lo anterior, también fue advertido por Valdano, quien mencionaba que los jugadores profesionales parecen entrar en lo que él concibe como una "puerta giratoria", figura que él usa para graficar la fragilidad de la estadía de un jugador en un equipo, dando a entender que con la facilidad con la que un jugador puede ser contratado, también puede ser retirado. Sobre el particular, el autor afirma lo siguiente:

Debido a la necesidad de los clubes de saldar sus números rojos y a la ansiedad de algunos representantes por aumentar sus números negros, muchos jugadores salen tan jóvenes que ni siquiera parecen conocer el mecanismo de estas puertas. De modo que entran $y$, a idéntica velocidad, salen por el mismo lugar. Cada temporada vuelven al campeonato nacional varios jugadores que apenas un año antes habían llegado a Europa a cumplir un sueño. Pero al fútbol europeo uno tiene que ir aprendido, no a aprender. (...) Como la avaricia no tiene fin, la cadena de salidas apresuradas sigue sumando eslabones. (...) Algunos de ellos no volverán a levantar la cabeza, porque esa experiencia frustrada afectará a la parte más delicada de la personalidad de un futbolista: la confianza (Valdano, 2016, pág. 167).

Vista así la situación del mundo deportivo, es de vital importancia entrar en detalle acerca de todas las implicancias que este tipo de escenarios podría producir.

Como ya mencionamos, el deporte también se ha visto afectado por el progreso desmedido de esta "cultura del descarte", el cual no termina sino beneficiando a ciertas personas que buscan lucrar a costa de estas "marcas" comerciales en que se han convertido los futbolistas, sobre todo aquellos que, por su temprana edad, se encuentran expuestos a muchos más riesgos, considerando la necesidad del acompañamiento de sus familias.

Sobre el particular, cada vez son más comunes los casos de futbolistas jóvenes, muchos de ellos entre los 12 a 18 años, que, por motivos deportivos, son alejados de sus familias, de sus casas, de sus centros de estudios y son llevados a nuevos destinos con la posibilidad de hacer carrera allí. Si bien la intención es notable, pareciera que se infravalora la necesidad de contar con un ambiente sano que pueda guiar y aconsejar al joven.

Todo lo anterior conlleva a que reflexionemos sobre la realidad de los deportistas, quienes, como mencionamos, debido a las promesas que la sociedad de hoy les hace en relación al factor económico, son privados de una serie de derechos, impidiéndoles ejercer libremente su personalidad y renunciando a muchos detalles de su vida privada.

\section{Reflexiones en torno a la "sumisión consentida"}

Cabe indicar en este punto, el largo debate en relación al supuesto consentimiento ante la "sumisión" de este tipo de tratos. Sobre el particular, Michael Sandel nos plantea la idea acerca de que "solo podremos elegir con libertad si no estamos indebidamente presionados (por la necesidad de dinero, por ejemplo) y sí razonablemente bien informados sobre las demás posibilidades" (2011, p.113).

Así, incluso se podría poner en tela de juicio el consentimiento de los atletas en 
estos contratos debido a la inequidad de la información de las posibles consecuencias, las cuales no son advertidas debidamente debido a la influencia del contexto actual, el cual precondiciona a estos jóvenes o a sus familias hacia la búsqueda de determinados bienes, sin tomar en cuenta las posibles repercusiones negativas.

Consideramos que actualmente la humanidad vive tiempos de muchos cambios en lo que respecta al respeto de los derechos fundamentales de la persona. Así, es relativamente sencillo poder dilucidar varias situaciones donde la persona es afectada directamente por una serie de factores externos, los cuales no harían sino vulnerar su desarrollo íntegro.

No obstante, el primer paso para un cambio sistémico es comenzar por corroborar la existencia de un daño a la persona dentro de un determinado ámbito. Al respecto, dentro de nuestro estudio, dicho ámbito corresponde al contexto deportivo. De ese modo, se podrían diseñar directrices específicas para poder subsanar adecuadamente el daño a la persona en ese ámbito.

Así, este fenómeno adquiere un nuevo matiz cuando afecta a los adolescentes. Pues, como es conocido, estos presentan características específicas acordes a su edad, haciendo que las afectaciones provocadas por una idea superficial y mercantilista del deporte tengan repercusiones más nocivas para su formación humana.

Sobre lo anterior, un fuerte sector en la actualidad defiende la idea que, más allá de los valores que se le pueda inculcar a un deportista, lo más relevante es asegurarle a este una supuesta calidad de vida mínima basada únicamente en el factor monetario. Sin embargo, esta visión de desarrollo no contempla otro tipo de condiciones, -como por ejemplo el acompañamiento de la familia o la debida supervisión de un staff psicológico- que también deberían asegurar la formación humana de un atleta, sobre todo si es menor de edad.

Como ya hemos venido denunciando, los deportistas, actualmente, son vistos como meras máquinas, a los que se les pueden exigir resultados y triunfos, incluso a costa de su sufrimiento y el poco ejercicio de sus libertades individuales. Así, se crea el concepto de "hombre marca" como un nuevo tope en lo que respecta a la deshumanización del deporte, creando figuras idealizadas de deportistas dedicadas a vender su propia imagen como si de una marca comercial se tratara, obviando cualquier tipo de interacción del atleta con la realidad y creando una imagen "comercializable" de este.

Por ello, la preocupación es que los adolescentes que se están preparando actualmente para poder desempañarse como futbolistas de élite en el futuro están expuestos a todo este tipo de visiones. El mercado deportivo cada día reduce más la edad de los futuros atletas, por lo que es común que observadores de varias instituciones deportivas estén en búsqueda de deportistas más jóvenes para realizar negocios.

Del mismo modo, otra cuestión que debe motivar futuros estudios es dilucidar el rol de los padres de familia en este ámbito. $Y$ es que, actualmente, uno de los dilemas morales que los padres tienen durante la adolescencia de sus hijos es el grado de límites que deberían imponerles. En el caso concreto, debería haber ciertas nociones que les permitan discernir entre el apoyo que deberían mostrarles a sus hijos por la carrera que han elegido (futbolista) y las posibles 
implicancias negativas que podría tener. De esta forma, consideramos que el acompañamiento de los padres resulta crucial en la formación de los implicados. Precisamente por ello, es que se debe revalorizar su rol en el desarrollo integral de los futuros futbolistas.

\section{Hacia una nueva perspectiva: el "Enfoque de las Capacidades" como alternativa ética}

A partir de todo lo expuesto en las páginas precedentes, donde presentamos la necesidad por plantear nuevos estándares éticos en relación al deporte, creemos importante mencionar a una de las teorías éticas más destacables de los últimos años: El enfoque de las Capacidades.

Sobre el particular, dicho enfoque surge de la teoría de la justicia de Amatya Sen, ganador del Premio Nobel en economía en 1998. Sen, quien es un crítico de la visión utilitarista del desarrollo, ha mostrado su inconformidad respecto de dicho modelo, planteando la insuficiencia de este para medir el bienestar de los individuos. Al respecto, el referido autor menciona:

Por ejemplo, los principios utilitaristas, se basan en última instancia, sólo en las utilidades, y aunque por el camino puedan tenerse muy en cuenta los incentivos, es la información sobre la utilidad la que se considera a la larga la única base correcta para evaluar la situación o para evaluar actos o normas. En versión clásica del utilitarismo, tal como la formula Jeremy Bentham, la utilidad es el placer, la felicidad o la satisfacción y, por tanto, todo gira en torno a estos logros mentales. (...) Por otra parte, al modelo agregado del utilitarismo no le interesa, ni es sensible a la distribución real de las utilidades, ya que solo se fija en la utilidad total de todas las personas consideradas en su conjunto. Esto hace que la base de información sea muy reducida, y esta insensibilidad general es una importante limitación de la ética utilitarista (Sen 1999, 56).

En ese sentido, a partir de la crítica que se establece al modelo predominante de desarrollo, se comienza a erigir una nueva visión al respecto. Así, a partir de las reflexiones de Sen, Martha Nussbaum5, desarrolla lo que ella denomina el "Enfoque de las Capacidades".

Al respecto de este enfoque, la autora menciona lo siguiente:

El enfoque de las capacidades puede definirse provisionalmente como una aproximación particular a la evaluación de la calidad de vida y a la teorización sobre la justicia social básica. En él se sostiene que la pregunta clave que cabe hacerse cuando se comparan sociedades y se evalúan conforme a su dignidad o a su justicia básica es: ¿Qué es capaz de hacer y de ser cada persona? Dicho de otro modo, el enfoque concibe a cada persona como un fin en sí mismo y no se pregunta solamente por el bienestar total o medio, sino por las oportunidades disponibles para cada ser humano (Nussbaum 2012, 38).

En ese sentido, la autora expone una serie de capacidades que tendrían que asegurarse para poder medir adecuadamente la calidad de vida de un determinado individuo. Así, Nussbaum

\footnotetext{
${ }^{5}$ Al respecto, la referida autora menciona, en la misma línea que Sen, que "la renta y la riqueza no son buenos indicadores representativos de lo que las personas son realmente capaces de hacer y de ser. Cada individuo tiene necesidades diferentes de recursos para alcanzar a un nivel similar de funcionamiento, y también tiene facultades y aptitudes distintas para convertir recursos e funcionamientos" (Nussbaum 2012, 78).
} 
expone que dichas capacidades serían las siguientes:

- Vida: Poder vivir hasta el término de una vida humana de duración normal.

- Salud física: Poder mantener buena salud, alimentación, así como de un lugar donde vivir.

- Integridad física: La capacidad de desplazarse libremente de un lugar a otro; del mismo modo, la garantía de no ser agredidos.

- Sentidos, imaginación y pensamiento: Poder utilizar nuestra capacidad imaginativa, de pensamiento y de razonamiento; asegurando una mínima educación básica para poder ejercerlas. Es el hecho de poder usar nuestra mente bajo la garantía de la libertad de expresión y pensamiento.

- Emociones: El hecho de poder sentir apego o duelo por cosas, personas e incluso con nosotros mismos. Involucra evitar la generación de un ambiente hostil para que la persona manifieste sus emociones.

- Razón práctica: Poder formar nuestra propia concepción del bien y el mal; así como reflexionar sobre la planificación de nuestra propia vida. En ese sentido, aquí se busca resguardar tanto la libertad de conciencia como la religiosa.

Afiliación: Que busca resguardar dos tipos de capacidades. Por un lado, la capacidad para poder vivir con y para los demás, reconociendo y mostrando interés por otros seres humanos $\mathrm{y}$ siendo capaces de unirse a otros por determinadas razones. Del mismo modo, se busca proteger la capacidad de disponer las bases sociales para evitar sentir humillación y sí respeto por nosotros mismos, esto es, que se nos trate como seres igualmente dignos, vetando todo tipo de actos discriminatorios.

- Otras especies: Poder vivir en una relación armoniosa con otros seres vivos, tanto animales como plantas.

- Juego: Poder reír, jugar y disfrutar de actividades recreativas

- Control sobre el propio entorno: Lo cual involucra dos tipos de capacidades. Por un lado, la capacidad política, que asegura la capacidad de poder ser partícipe de la vida política de su comunidad. Del mismo modo, hay una capacidad material, que involucra el poder de poseer propiedades y ostentar derechos de propiedad en igualdad de condiciones que los demás; del mismo modo, asegura la capacidad de poder trabajar como seres humanos en igualdad de condiciones, ejerciendo relaciones positivas de reconocimiento mutuo con los demás trabajadores (Nussbaum 2012, pp.53-56).

Como puede apreciarse, el "Enfoque de las Capacidades" es la posibilidad de ejercitar estas facultades las que van a determinar la calidad de vida de una persona. De esa forma, podemos apreciar cómo, desde las concepciones de Sen y Nussbaum, se busca dejar de lado la relación del desarrollo con el crecimiento económico, y se comienzan a tomar en cuenta otros factores al respecto.

De esta forma, considero que una perspectiva ética como la descrita por Nussbaum debe ser aplicada al mundo deportivo. Así, se podría priorizar, no solo la utilidad que se pueda desprender del performance de los atletas de élite, sino que esto debería delimitarse por la capacidad de ejercer sus derechos individuales básicos. 


\section{Conclusiones}

El deporte ha dejado de ser visto como una actividad destinada a acrecentar las virtudes humanas mediante el ejercicio físico, pasando a ser una de las industrias que más dinero capitaliza por año.

Actualmente, la industria deportiva es manejada bajo conceptos que no priorizan al deportista, sino que, por el contrario, los perciben como herramientas sobre las que se pueden obtener ingresos económicos.

Dentro de los contratos deportivos que los futbolistas de élite firman hoy en día no solo se estipulan cuestiones laborales, sino que, debido a la desinformación entre las partes, permiten que el deportista ceda el ejercicio de una serie de sus libertades individuales a la institución deportiva.

De ese modo, cuestiones sobre sus derechos de imagen o su libertad para contratar o expresarse quedan limitados según las estipulaciones que dictamine la institución a la que pertenece.

Este tipo de tratos afecta no solo a los deportistas de élite, sino que se traslada también a los menores de edad que se están preparando para convertirse en ello. En ese sentido, la industria deportiva está, progresivamente, en búsqueda de nuevos talentos cada vez más jóvenes.

Los menores de edad involucrados, al ser una población más vulnerable debido a sus edades, son afectados más raudamente por las repercusiones de los contratos deportivos actuales.
$>$ El "enfoque de las capacidades", debido a la trascendencia que da a las libertades individuales sobre la utilidad, puede ser propuesta como una perspectiva ética sobre la que pueden desarrollarse modificaciones al cómo se dan las relaciones con los deportistas hoy en día.

\section{Recomendaciones}

$>$ Es necesario que haya más estudios que reflexionen sobre cómo se ha venido desarrollando la industria deportiva. Sobre el particular, al ser un fenómeno que se ha acrecentado en los últimos años, aún no hay demasiados autores que hayan analizado las posibles implicancias de este tipo de enfoques desde la psicología, el derecho, la ética y la antropología.

$>$ Desde las mismas instituciones deportivas se debe realizar una retroalimentación sobre cómo han venido ejerciendo su control sobre los futbolistas que manejan, siendo críticos con las posibles implicancias que podrían generar en estos.

> Del mismo modo, es necesario que las instituciones deportivas no solo velen por una contraprestación material para los atletas, prescindiendo de otros tipos de necesidades que puedan tener, sino por ser considerados no solo como herramientas, sino como personas.

$>$ En ese sentido, en el caso de los menores, el estado de vulnerabilidad de estos debe ser considerado a sabiendas de las graves consecuencias que podría tener su rol como deportistas en su desarrollo humano. 
A su vez, el rol de los padres de familia es crucial para que, en caso de que un menor muestre interés en la profesión de deportista, pueda comprender las posibles implicancias de esta, mostrando comprensión y compañía en el proceso de toma de decisiones.

\section{Bibliografía}

Bauman, Zygmunt (2013). La cultura en el mundo de la Modernidad Líquida. Buenos Aires: Fondo de Cultura Económica.

Cappa, Á. (2004). ¿Y El Fútbol Dónde Está? Lima: Peisa.

El País (25 de febrero de 2016). Obtenido de: https://elpais.com/elpais/2016/01/25/medi a/1453741407_151970.html

García Romero, F. (2009). "Alabanza y Crítica del deporte en la literatura griega". En Materiales para la Historia del Deporte, VII 2009-ISSN, 1987, Asociación Andaluza de Historia del Deporte, pp. 9-22.

Francisco (2013). Exhortación apostólica Evangelii Gaudium.

Mbappé, K. (10 de octubre de 2018). "How Kylian Mbappé Stays Grounded". Revista
"The Time". (V. Walt, Entrevistador) Obtenido de http://time.com/collectionpost/5420315/kylian-mbappe-interview/

Nussbaum, M. (2012). Crear Capacidades. Barcelona: Paidós.

Ponzio, Augusto. (1974). Gramática transformacional e ideología política. Buenos Aires: Ediciones Nueva Visión.

Sandel, M. (2011). Justicia iHacemos lo que debemos? Barcelina: DeBolsillo

Sen, A. (1999). Development as Freedom. Oxford: Oxford University Press.

Touré, Y. (25 de enero de 2017). Touré critica a China: "El fútbol es lo primero, no el dinero". Diario "AS". (A. Fra, Entrevistador) Obtenido de https://as.com/futbol/2017/01/25/internaci onal/1485325593_032872.html

Transfermarkt. (11 de mayo de 2019). Obtenido de https://www.transfermarkt.es/spielerstatistik/wertvollstespieler/marktwertetop

Valdano, J. (2016). Fútbol: El Juego Infinito. El nuevo fútbol como símbolo de la globalización. Barcelona: Conecta. 